This document was prepared in conjunction with work accomplished under Contract No. DE-AC09-96SR18500 with the U.S. Department of Energy.

This work was prepared under an agreement with and funded by the U.S. Government. Neither the U. S. Government or its employees, nor any of its contractors, subcontractors or their employees, makes any express or implied: 1 . warranty or assumes any legal liability for the accuracy, completeness, or for the use or results of such use of any information, product, or process disclosed; or 2 . representation that such use or results of such use would not infringe privately owned rights; or 3 . endorsement or recommendation of any specifically identified commercial product, process, or service. Any views and opinions of authors expressed in this work do not necessarily state or reflect those of the United States Government, or its contractors, or subcontractors. 


\title{
AIR PASSIVATION OF METAL HYDRIDE BEDS FOR WASTE DISPOSAL
}

\author{
J. E. Klein and R. H. Hsu
}

Savannah River National Laboratory: Aiken, SC 29808, james.klein@srnl.doe.gov

\begin{abstract}
Metal hydride beds offer compact, safe storage of tritium. After metal hydride beds have reached the end of their useful life, the beds will replaced with new beds and the old beds prepared for disposal. One acceptance criteria for hydride bed waste disposal is that the material inside the bed not be pyrophoric. To determine the pyrophoric nature of spent metal hydride beds, controlled air ingress tests were performed. A simple gas handling manifold fitted with pressure transducers and a calibrated volume were used to introduce controlled quantities of air into a metal hydride bed and the bed temperature rise monitored for reactivity with the air.
\end{abstract}

A desorbed, $4.4 \mathrm{~kg}$ titanium prototype hydride storage vessel (HSV) produced a $4.4^{\circ} \mathrm{C}$ internal temperature rise upon the first air exposure cycle and a $0.1^{\circ} \mathrm{C}$ temperature rise upon a second air exposure. A total of $346 \mathrm{scc}$ air was consumed by the bed (0.08 scC per gram Ti).

A desorbed, $9.66 \mathrm{~kg} \mathrm{LaNi}_{4.25} \mathrm{Al}_{0.75}$ prototype storage bed experienced larger temperature rises over successive cycles of air ingress and evacuation. The cycles were performed over a period of days with the bed effectively passivated after the $12^{\text {th }}$ cycle. Nine to ten STP-L of air reacted with the bed producing both oxidized metal and water.

\section{INTRODUCTION}

The Savannah River Site (SRS) Tritium Facilities utilize a variety of metal hydride material in process vessels, or beds, for the safe processing and storage of tritium. Metal tritide beds have a finite useful life due to impurities in the process gas that reduce the bed's useful capacity, He-3 retention in the hydride which alters its ability to store and/or delivery gas in a desired cycle time, or has a limited design life.

When replacing a bed, the tritium content is typically reduced by desorption and isotopic exchange ${ }^{1}$ in preparation for disposal. Before disposal, the bed must be non-pyrophoric. Hydride absorption/desorption cycling decrepitates many hydrides into powders that will react with air. In one instance, nominally $8 \mathrm{~kg}$ of desorbed, but not passivated, $\mathrm{LaNi}_{4.25} \mathrm{Al}_{0.75}$ was removed from a test $\operatorname{bed}^{2}$ and produced visible oxidation of the material (glowing red particles) inside a chemical hood. An in-situ process used opened the bed valve to room air for several months to passivate the hydride by diffusion of air into the vessel.

To quantify when a metal hydride is rendered nonpyrophoric, tests conducted measured the amount of air which reacted with a metal hydride. Batch-wise quantities of air were introduced into the evacuated bed. The air was allowed to react inside the bed before being evacuated. Air exposure/evacuation cycles were repeated until the bed appeared to be non-reactive with air.

\section{BACKGROUND}

The thermal response of metal hydrides with air are typically reported as part of accident scenario studies ${ }^{3,4}$. Many times beds prepared for disposal are handled by facility operations personnel and go as unpublished work. A gas such as argon is mixed with 2 vol\% to $20 \mathrm{vol} \%$ oxygen and then administered to the vessel in either a batch or flow mode. Depending on the vessel design and temperature measurement instrumentation, maximum temperature criteria are established. The oxygen containing gas is introduced until a thermal response is no longer detectable and the bed deemed ready for disposal.

Air inside a metal hydride bed can react with the metal hydride or residual hydrogen to produce water or possibly ammonia. Previous work has looked at airingress into uranium beds ${ }^{3,4}$, the pyrophoric nature of small metal hydride samples with air ${ }^{5}$, and also with oxygen, and nitrogen ${ }^{6}$. In these tests, uranium and $\mathrm{ZrCo}$ reacted both with oxygen and nitrogen while experience at SRS/SRNL and the work of Longhurst ${ }^{5}$ has shown La$\mathrm{Ni}-\mathrm{Al}$ alloys utilized in SRS tritium storage beds do not react with nitrogen.

The reaction of air within a metal hydride bed can be inferred by the thermal response of the vessel. If system volumes are known, gas expansions can determine if oxygen is being consumed by the bed or by comparing the gas composition before and after it enters a bed. The 
purpose of this work was to perform air passivation tests on two metal hydride beds to determine when the materials were no longer reactive with air. Thermal measurements were made along with pressure-volumetemperature calculations to determine complete passivation of the materials.

\section{EXPERIMENTAL}

\section{A. Experimental Test Manifold}

Figure 1 is a simplified manifold schematic used for the air passivation studies. Gases connected to the manifold were research grade helium (> 99.9995 vol\% purity) and air from the building compressed air supply system. Vacuum was supplied by an Alcatel molecular drag pump backed by a diaphragm pump. The calibrated volume was nominally 3.8 liters and the two pressure transducers (PTs) were calibrated 1.33 MPa (10,000 torr) MKS 690 Baratrons. The system was leak-checked and volume calibrated.

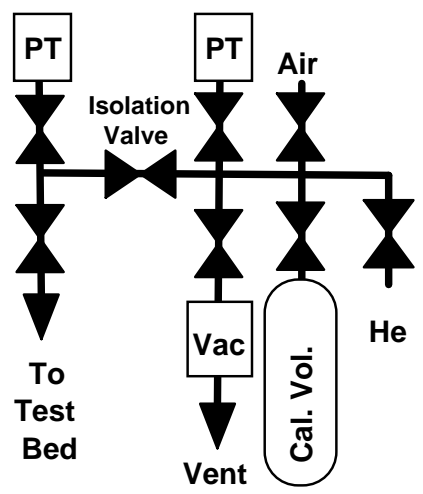

Fig. 1. Air Passivation System Schematic

\section{B. Hydride Storage Vessel (HSV) Tests}

A prototype titanium hydride storage vessel (HSV$\mathrm{P} 1$ ), described in a previous publication ${ }^{7}$, was used for this air passivation study. HSV-P1 contained $4.4 \mathrm{~kg}$ of Ergenics Hy-Stor $106^{\circledR}$ titanium and had a void volume of 3.997 liters.

Additional HSV-P1 cycles since the previous publication $^{7}$ included a partial $5^{\text {th }}$ absorption cycle to determine its thermal response during protium absorption with the vessel was wrapped in a heating mantle and a $5^{\text {th }}$ desorption cycle which produced an over pressure of 160 $\mathrm{Pa}\left(1.2\right.$ torr) at $690^{\circ} \mathrm{C}$ : an estimated hydrogen residual of $0.060 \mathrm{Q} / \mathrm{M}$ (using isotherm data) or $62 \mathrm{STP}-\mathrm{L}$. The $6^{\text {th }}$ absorption cycle added gas in nominally 200 STP-L aliquots to study wall stresses of the vessel when hydrided $^{8}$.

The $6^{\text {th }}$ HSV-P1 desorption cycle was performed in a horizontal position through both process connections using a different manifold system. The furnace set point was initially set to $700^{\circ} \mathrm{C}$ and gas desorbed for 20 hours using an Alcatel 5030 molecular drag pump backed by a Varian PTS 300 series tri-scroll pump. The furnace set point was then set to $800^{\circ} \mathrm{C}$ and the vessel evacuated for another 28 hours. The final rate-of-rise pressure was 370 $\mathrm{Pa}(2.8$ torr $)$ at $793^{\circ} \mathrm{C}$. This temperature and pressure were beyond the range of the existing isotherm data (Klein, 2002), but it was speculated that the residual hydride gas inventory was at least as low as that obtained during the $5^{\text {th }}$ desorption cycle. The complete hydride cycle history for HSV-P1 is shown in Fig. 2.

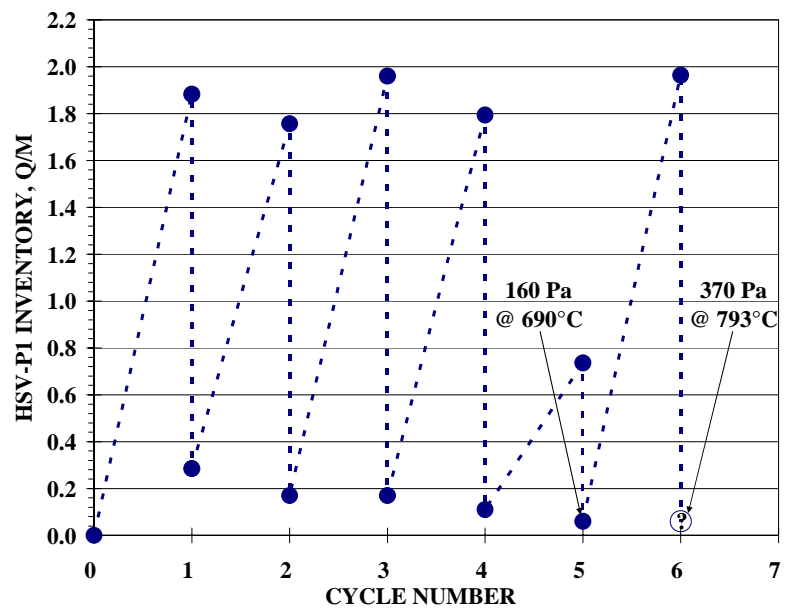

Fig. 2. HSV-P1 Hydride Cycling History

After the $6^{\text {th }}$ desorption cycle, the HSV valves were closed and the vessel cooled to room temperature. The vessel was removed from the furnace, and rotated to a vertical position. The vessel's long process gas connection tube was connected to the air passivation system shown in Figure 1 using a 6.35 mm (1/4 inch) O.D. copper line. Eight days elapsed between the start of the bed evacuation and the start of the air passivation tests.

The copper line and the manifold were evacuated and the line isolated from the system. The system was filled with $281 \mathrm{kPa}$ (2110 torr) air, the volumes up to the HSV valve determined by gas expansion, and then the air was allowed to enter the HSV for 197 minutes. The vessel and manifold were then evacuated for 210 minutes before HSV isolation, manifold repressurization with air and 
expansion again into the HSV for another 19 minutes before final HSV valve closure.

\section{Four-Inch Short Hydride (FISH) Bed Tests}

A prototype $\mathrm{LaNi}_{4.25} \mathrm{Al}_{0.75}$ hydride storage bed (stress bed 01 or SB01) described in a previous publication ${ }^{9}$, was used for these air passivation study. SB01, a four-inch, short hydride (FISH) prototype vessel used for hydride induced wall stress measurements contained $9.66 \mathrm{~kg}$ of Ergenics Hy-Stor $210^{\circledR} \mathrm{LaNi}_{4.25} \mathrm{Al}_{0.75}$ hydride after the $2^{\text {nd }}$ hydride fill. SB01 had four thermocouples (TCs) ${ }^{9}$ : TC04 was inserted into the hydride material and entered the bed through its fill port, TC05 was within the bed heater cartridge, TC06 was attached to the exterior of the bed 5.7 $\mathrm{cm}$ (2.25 inches) from the end with the gas inlet tube, and TC07 was attached to the exterior of the bed $5.7 \mathrm{~cm}(2.25$ inches) from the end with the fill port.

The vessel had undergone a number of hydride absorption/desorption and thermal cycles as illustrated in Figure 3 . The bed, connected to the Figure 1 manifold with a stainless steel flex line, was "baked-out" after its $35^{\text {th }}$ cycle with a heater $400^{\circ} \mathrm{C}$ set point temperature and evacuated for 42 hours before back-filling with helium and cooling the bed. Fifteen days elapsed between the start of the bed bake-out and the start of the air passivation tests.

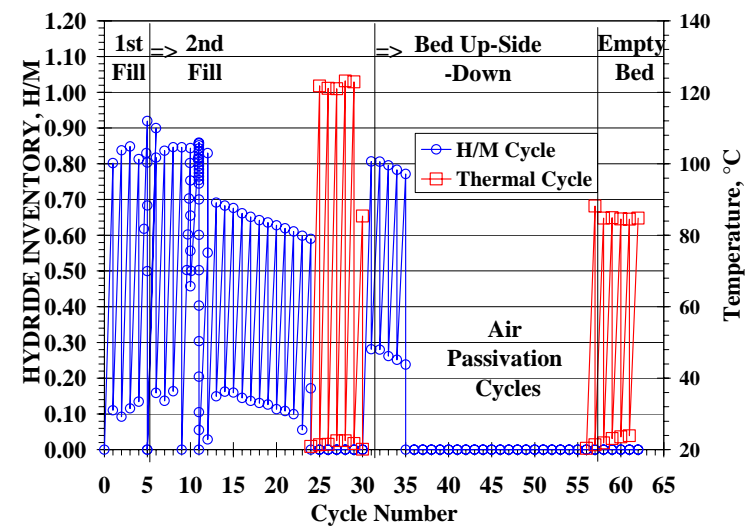

Fig. 3. FISH Bed SB01 Cycling History

The manifold and bed were evacuated to $2.4 \mathrm{~Pa}$ (18 microns) before valving-off the bed from the manifold. The system was filled with helium to $507 \mathrm{kPa}$ (3800 torr) and gas expansion used to determine a bed void volume of 1.63 liters. The helium was evacuated from the bed and manifold and the bed isolated from the manifold via the manifold isolation valve.
SB01 experienced numerous air passivation cycles. After evacuation, the bed was isolated for the manifold and the system filled with air to $507 \pm 1 \mathrm{kPa}$ (3800 \pm 10 torr). The isolation valve was then opened to expose the bed to the air. Typically after 30 minutes, the bed and manifold system were evacuated and the bed isolated so the calibrated volume could be refilled with air. The cycle of bed evacuation, bed isolation, and bed air exposure was repeated 21 times. After the $21^{\text {st }}$ cycle, the bed was disconnected from the flex line and the hydride removed from the bed.

\section{RESULTS}

\section{A. HSV/Titanium Results}

Figure 4 shows the HSV-P1 air passivation test temperature and pressure changes. Figure 4 pressures include the initial manifold pressure, the pressure after air expansion into the copper line, and the pressure after air expansion into HSV-P1.

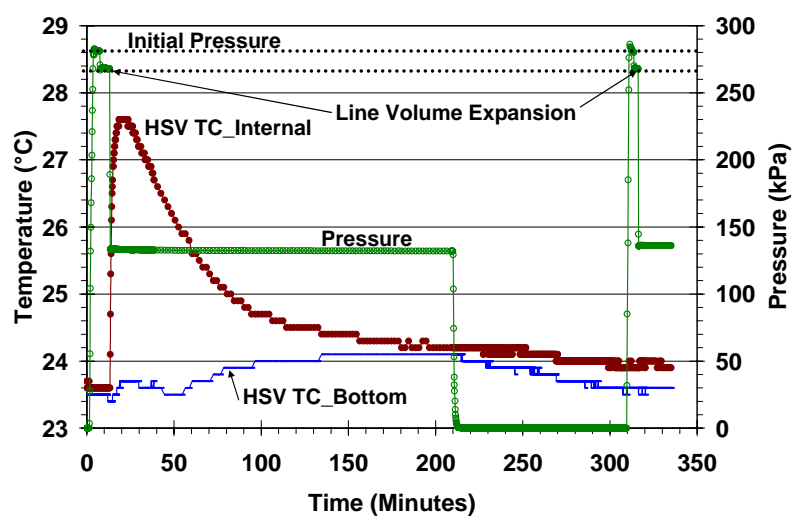

Fig. 4. HSV-P1 Air Passivation Results

Figure 4 shows for the first air introduction, the HSV the internal temperature increased $4.0^{\circ} \mathrm{C}$ in 5 minutes, was constant for 5 minutes, and then started decreasing. The HSV bottom thermowell TC took 24 minutes to reach a maximum temperature increase of $0.7^{\circ} \mathrm{C}$ before decreasing. For the $2^{\text {nd }} \mathrm{HSV}$ air introduction, the HSV internal temperature increased $0.1^{\circ} \mathrm{C}$ and a temperature rise at the bottom was not detected.

For the first air exposure, the gas expansion into the evacuated HSV, in the absence of any reaction, would give a calculated pressure of $137 \mathrm{kPa}$ (1025 torr) while the measured pressure after 196 minutes was $132 \mathrm{kPa}$ (991 torr). This gives 346 scc of gas consumed by the HSV. For the second air exposure, the final measured 
pressure was within $0.3 \mathrm{kPa}$ (2.5 torr) of the pressure calculated without any gas consumption.

\section{B. FISH/LaNi ${ }_{4.25} \mathrm{Al}_{0.75}$ Bed Results}

Figures 5, 6, and 7 shows SB01 air passivation TC05 temperature and pressure changes for air exposure cycles 1 through 4, (C\#01-C\#04), C\#05-C\#12, and C\#13-C\#20, respectively. Figure 5 also shows the initial helium expansion pressure change used to calculate the bed void volume. The pressure range in Figures 6 and 7 were shown over a smaller range than Figure 5 to illustrate the slower rate of pressure change during these cycles.

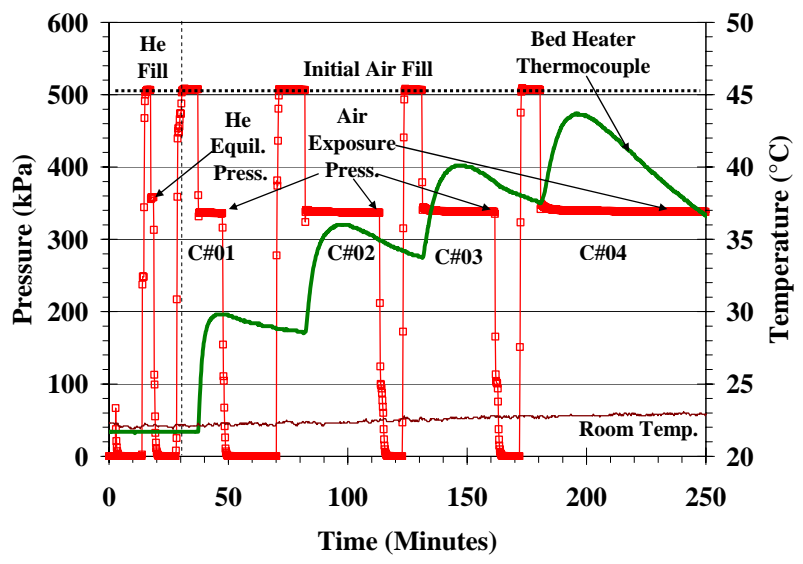

Fig. 5. SB01 Air Passivation Cycle \#01-04 Results

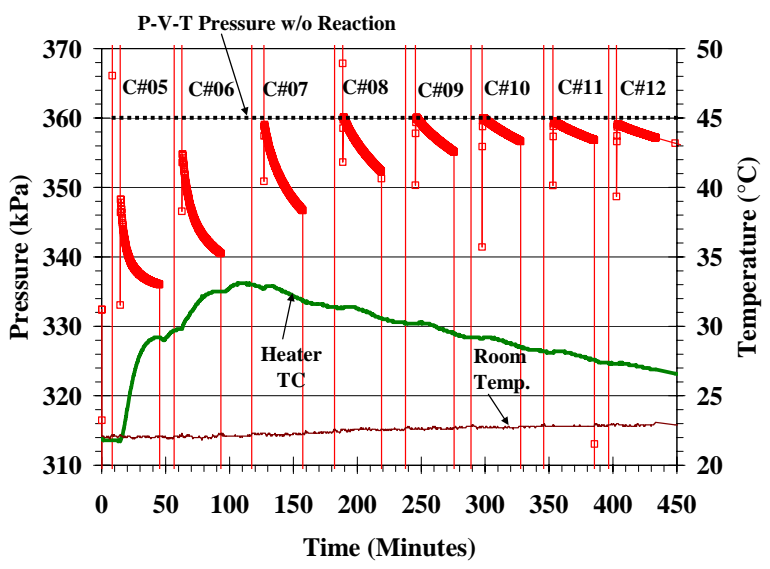

Fig. 6. SB01 Air Passivation Cycle \#05-12 Results

Not shown in Figures 5, 6, and 7 are the relatively long delays between $\mathrm{C} \# 04$ and $\mathrm{C \# 05}$, and between $\mathrm{C} \# 12$

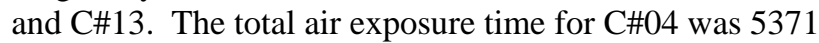
minutes (89.5 hours) and for C\#12, 985 minutes (16.4 hours). The air exposure results for $\mathrm{C} \# 21$ were similar to the results for $\mathrm{C} \# 20$ even after a 2650 minute (44.2 hours) air exposure and the results not shown.

The evacuation times for SB01 varied between 6 to 24 minutes with SB01 isolated from the system for an additional 3 to 12 minutes while the system was refilled with compressed air. Air exposure cycles were nominally 30 minutes except for 10 minutes for $\mathrm{C} \# 01$ and 21 minutes for C\#02, C\#05, and C\#09.

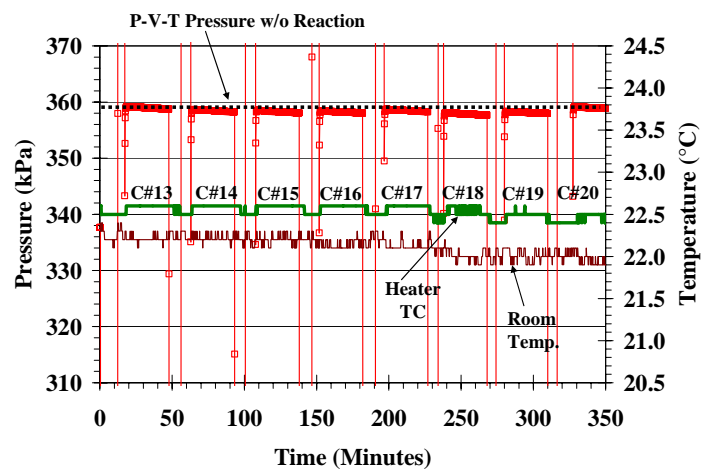

Fig. 7. SB01 Air Passivation Cycle \#13-20 Results

Figure 8 shows the gas reacted for each air exposure cycle along the left axis when using TC05 and TC06 for

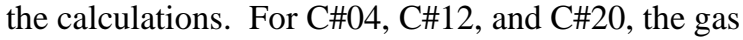
reacted at 30 minutes during these cycles are shown with dashed lines and solid filled circles in Figure 8. The cumulative gas reacted is shown on the right axis in Figure 8 when using TC05 and TC06 in the calculations.

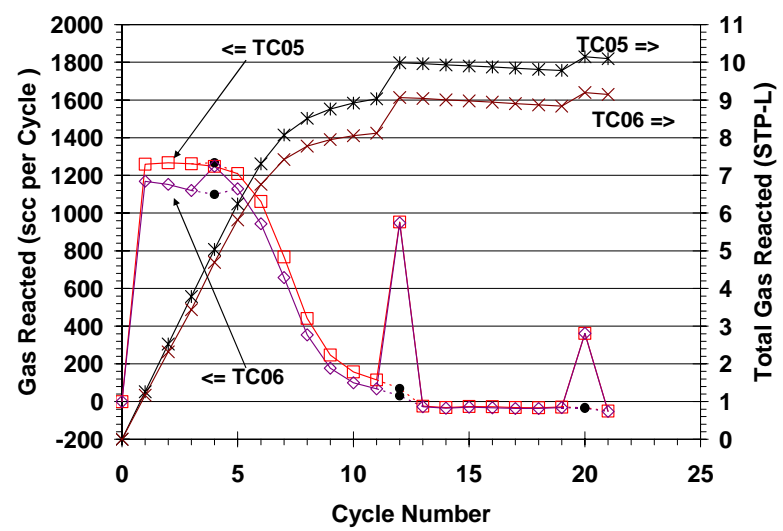

Fig. 8. SB01 Air Consumption Results

\section{DISCUSSIONS}


Figure 4 showed an easily measurable temperature rise for the HSV after the first air exposure and the thermal transients, although small, were virtually complete when the second air exposure cycle was started. It is not known if the $0.1^{\circ} \mathrm{C}$ internal temperature increase in the vessel was due to the compressive heating of the air entering the vessel. The $0.3 \mathrm{kPa}$ (2.5 torr) difference in the pressure calculated without reaction and the pressure measured is within the calibration error tolerance of system volumes and pressure transducers.

Assuming the 346 scc of gas consumed by HSV-P1 is oxygen, adiabatic temperature rise calculations were performed using the heat of formation of $\mathrm{TiO}_{2}$ as -225 $\mathrm{kcal} / \mathrm{mole}$ [Ref. 10, p. 3-154], the heat of formation of liquid water as $-68.3 \mathrm{kcal} / \mathrm{mole}$, and the the heat capacity of titanium at $22^{\circ} \mathrm{C}$ as $7.3 \mathrm{cal} / \mathrm{mole}^{\circ} \mathrm{C}$ [Ref. 10 , p. 3-134]. For the $1^{\text {st }} \mathrm{HSV}$ air ingress, the adiabatic titanium temperature rise would be $5.2^{\circ} \mathrm{C}$ for $\mathrm{TiO}_{2}$ formation and $3.2^{\circ} \mathrm{C}$ for liquid water formation. Although the titanium may not react completely to $\mathrm{TiO}_{2}$, the measured $4.0^{\circ} \mathrm{C}$ temperature rise indicates that some titanium-oxygen compound was formed: the evacuated gas was not analyzed for water or other species.

Compared to the pressure obtained from helium expansion into the bed, the pressure after $\mathrm{C} \# 01$ is over 20 $\mathrm{kPa}$ (150 torr) lower and easily measured. Figure 9 shows the temperature rise at the start of each cycle for the first four cycles with the vertical marks indicating when bed evacuation started for the first three cycles. The continuity of the temperature rise lines in Figure 9 after initiating post-test bed evacuations was interpreted as the reaction of the bed being essentially complete with the available air/oxygen in the bed void space.

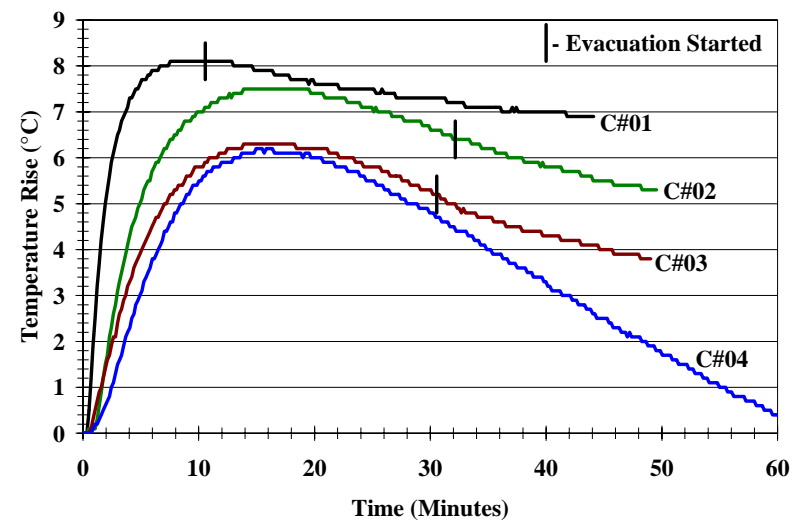

Fig. 9. SB01 Temperature Rises for Cycles \#01-\#04

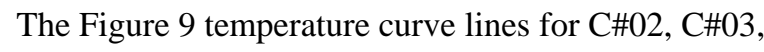
and $\mathrm{C \# 04}$ have similar shapes with $\mathrm{C \# 02}$ having the highest temperature rise and $\mathrm{C \# 03}$ and $\mathrm{C \# 04}$ within $0.1^{\circ} \mathrm{C}$ of one another. The faster decrease in temperature rise for C\#04 after its maximum was attributed to the bed being hotter, and thus losing heat faster, than for the previous cycles.

Figure 10 is a plot of Figure 5 with the same pressure range scale as Figure 6 . It shows for $\mathrm{C} \# 01$ that the pressure quickly is near its final value indicating that the bed has reacted with the available oxygen in the bed. Although the approach to a final pressure is slightly slower for cycles \#02 through \#04, Figure 8 indicates that the bed has consumed essential all the available oxygen inside the bed.

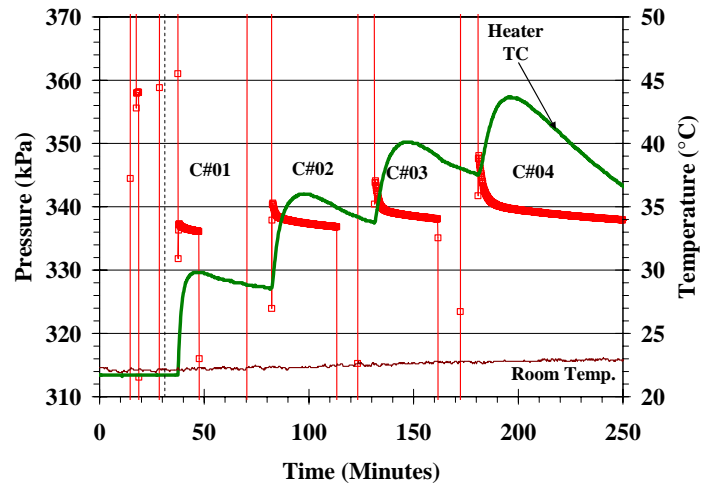

Fig. 10. SB01 Temperature Cycle \#01-04 Results

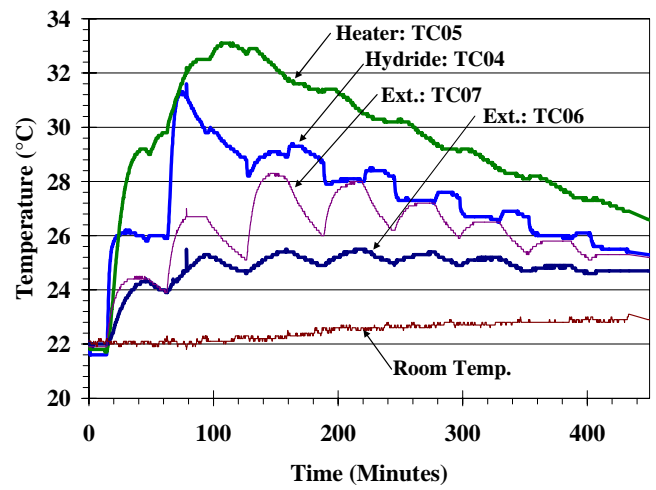

Fig. 11. SB01 Temperatures During Cycles \#05-12

Figure 6 shows that final pressure before bed evacuation increases for each of the cycles \#05-\#12 and that the heater temperature reaches a maximum during 
C\#06 and then is lower for each additional cycle. The increase in heater temperature during bed evacuation between cycles was due to the thermal lag of the heater in the heaterwell. Figure 11 shows the correlation of temperatures measured during C\#05-12.

Figure 8 used TC05 (the highest temperature) and TC06 (the lowest temperature) to demonstrate the variation in the amount of gas reacted when using different temperatures in the calculations. Using TC05 values, 8839 scc of gas reacted compared to 7681 scc when using TC06 values: a 15\% difference. It is interesting to note that except for C\#20, cycles \#13 through \#21 calculated negative amounts of gas reacted: in the range of 24 to 50 scc.

Adiabatic temperature rise calculations are harder to compute for SB01 due to the hydride being an alloy. Heats of formation are readily available for $\mathrm{La}_{2} \mathrm{O}_{3}, \mathrm{NiO}$, and for $\mathrm{Al}_{2} \mathrm{O}_{3}$ and using the alloy stoichiometry, it would take 6.875 atoms of atomic oxygen to completely oxidize one atom of hydride alloy to the previously listed phases: 1821 STP-L of molecular oxygen.

What was not clear from the figures was that when C\#01-04, and C\#05-08 where being performed, the evacuation of the bed to a target starting pressure of less than or equal to $40 \mathrm{~Pa}$ (0.3 torr) took longer and for cycles C\#07-12 and C\#21 were not obtained - the highest bed starting pressure was $120 \mathrm{~Pa}$ (0.9 torr) for C\#08. This increased difficulty in evacuating the bed was attributed to the formation of water from residual hydrogen in the hydride.

\section{CONCLUSIONS}

The passivation of spent metal hydride beds is sometimes necessary before the bed can be deemed nonpyrophoric and sent for disposal. Titanium filled vessels do not require air passivation before disposal since there is only a mild reaction with air creating a temperature rise of $4^{\circ} \mathrm{C}$. If the vessel is breached during burial, the reaction with air will be slow and will not create a problem for the burial location.

La-Ni-Al alloy beds do require passivation before being sent for disposal. The reaction of air, or some other oxygen containing gas, with the metal hydride can be inferred by monitoring the bed temperature and/or pressure when exposed to air. Batch-wise exposure to air controls the maximum temperature rise the bed can experience and successive passivation cycles can be interrupted if bed temperature increases become a concern. For the processing of bed containing tritium, it is recommended that a drier bed be installed on the outlet of the bed to collect tritiated water formed during the passivation process.

\section{ACKNOWLEDGMENTS}

The author would like to thank Jody Dye and Eddy Estochen for their support of this work. This paper was prepared in connection with work done under Contract No. DE-AC09-96SR18500 with the U. S. Department of Energy.

\section{REFERENCES}

[1] J. E. Klein and J. R. Wermer, "Isotopic Exchange for Metal Hydride Bed Disposal," Fusion Technol., 41, 776 (2002).

[2] S.T. McKillip, C. E. Banister, and E. A. Clark, "Stress Analysis of Hydride Bed Vessels Used For Tritium Processing,” Fusion Technol., 21, 1011 (1992).

[3] L. K. Heung, "Tritium Transport Vessel Using Depleted Uranium,” Fusion Technol., 28, 1385 (1995).

[4] G. R. Longhurst, A. G. Heics, W. T. Shmayda, R. L. Rossmassler, "Experiemental Evaluation of the Consequences of Uranium Bed Air-Ingress Accidents,” Fusion Technol., 21, 1017 (1992).

[5] G. R. Longhurst, "Pyrophoricity of TritiumStorage Bed Materials,” Fusion Technol., 14, 750 (1988).

[6] A. N. Perevezentsev, A. C. Bell, R. Lasser, and L. A. Rivkis, "Safety Aspects of Tritium Storage in Metal Hydride Form,” Fusion Technol., 28, 1404 (1995).

[7] J. E. Klein, “A 1600 Liter Tritium Hydride Storage Vessel,” Fusion Technol., 41, 764 (2002).

[8] E. A. Clark and M. J. Pechersky, "Hydride Storage Vessel Wall Stress Measurements," Savannah River Site Technical Report WSRCTR-97-0187 (1997).

[9] E. G. Estochen and J. E. Klein, "Metal Hydride Wall Stress Measurements on a Four-Inch Short (FISH) Bed,” Fusion Technol., 48, 79 (2005).

[10] R. H. Perry and D. Green, eds., "Perry’s Chemical Engineer's Handbook”, 6 ${ }^{\text {th }}$ Ed. 1984. 